\title{
Ikasleen arrazoibide kognitiboa aztertzeko euskarazko proba. Ezaugarriak eta sexuaren araberako desberdintasunak
}

Paula Elosua Oliden

Gizarte Psikologia eta Portaera Zientzien Metodologia Saila Psikologia Fakultatea UPV/EHU

María Egaña Elosua

Humanitate eta Hezkuntza Zientzien Fakultatea Mondragon Unibertsitatea

DOI: $10.1387 / \tan t a k .17866$

GAKO-HITZAK: arrazoibide kognitiboa, sexuaren araberako desberdintasunak, euskara, BPR

\section{SARRERA}

Giza adimena lehentasunezko gaia izan da psikologiarentzat, eta gaur egun interes horrek bizirik dirau. Horren adibide da test psikologikoen erabilerari buruzko ikerketek diotena. Europa mailan, esaterako, gaitasun intelektualak neurtzen dituzten testak dira test erabilienak; bai hezkuntza alorrean, bai erakundeen esparruan, eta baita psikologia klinikoan ere (Elosua eta Iliescu, 2012). Testak erabiltzeko, ordea, printzipio psikometrikoak errespetatzen dituzten tresnak eduki behar dira, eta orain arte Euskal Herrian ez dugu izan gure ikasleen gaitasun intelektualak neurtzeko berariazko probarik. Gabezia larri hori gainditzeko asmoarekin 2010. urtean Arrazoiketa-Proba Andanaren egokitze-prozesuari ekin zitzaion (Elosua eta Almeida, 2016), eta lan honen helburua Arrazoiketa-Proba Andanaren oinarri teorikoak azaltzea, horren ezaugarri psikometrikoak aztertzea eta sexuaren arteko desberdintasunak analizatzea da.

Arrazoiketa-Proba Andana («Bateria de Provas de Raciocionio», BPR; BPR hemendik aurrera) Georges Meuris (1969) belgikarrak garaturiko «Tests de Raisonnement Différentiel» proban oinarrituta dago. Andanaren helburua haur eta gazteen arrazoibide-gaitasunak ebaluatzea da; BPRk, 
adimenaren alderdi orokorra ebaluatzeaz gain, adimenaren faktore anitzeko andanek ohiz aztertzen dituzten osagaiak ere ebaluatzen ditu.

Adimenaren egituraz hitz egiterakoan, oro har bi dira lehian diharduten teoriak; batetik, adimenaren faktore orokorra, $g$ deritzona, defendatzen dutenak (Spearman, 1927), eta, bestetik, gaitasun intelektual desberdinak eta autonomoak aldarrikatzen dituztenak (Thurstone, 1938; Guilford, 1967). Bi posizio kontrajarri horien artean, ikuspuntu bateratzaile bat indartu da azken urteotan; horren arabera, gaitasun kognitiboek antolamendu hierarkikoa dute (Carroll, 2003; Cattell, 1963, 1971; Horn eta Noll, 1997; McGrew, 2005; Schneider eta McGrew, 2012; Vernon, 1961). Ikuspuntu horren adierazlerik nabarmenena Cattell-Horn-Carroll (CHC) izenez ezagutzen den teoria da. CHC ereduaren arabera adimena hiru geruzaren bitartez irudika daiteke. Lehen mailako geruza espektro estuko gaitasunek definitzen dute; horiek euren artean elkartu eta bigarren estratuko geruza sortzen dute. Bigarren geruzan bederatzi gaitasun definitu dira: (a) arrazoibide bizkorra, Gf ; (b) adimen gauzatua, Gc; (c) prozesatze kognitiboaren lastertasun, Gs; (d) iraupen laburreko oroimena, Gsm; (e) iraupen luzeko oroimena gordetzea eta berreskuratzea, Glr; (f) irakurtzeko eta idazteko gaitasuna, Grw; (g) zenbakizko arrazoibidea, Gq; (h) prozesamendu bisual-espaziala, Gv; eta (i) entzutezko prozesamendua, Ga. Gaitasun horiek guztiek osatuko lukete hirugarren geruza edo $g$ faktore orokorra.

Eredu hierarkikoarekin loturik, BPR andana ondoko gaitasunak neurtzeko asmoarekin sortu da (Ikus 1. irudia): (a) inteligentzia bizkorrarekin loturiko arrazoibide abstraktua, Gf; ( b) ulermenarekin edo inteligentzia

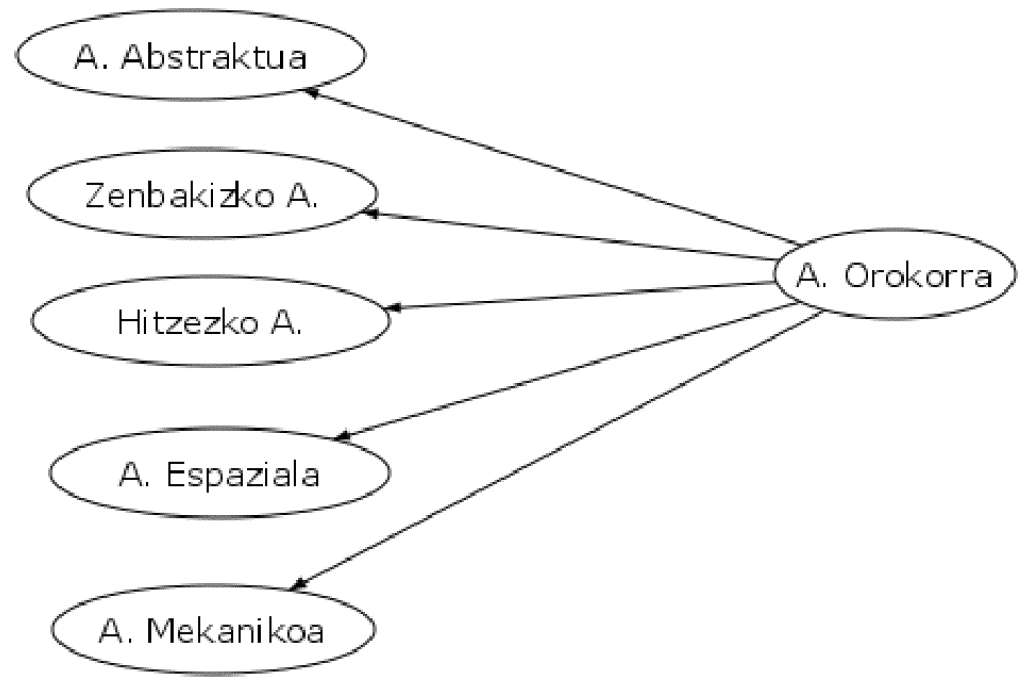

1. irudia

Arrazoiketa-proba andana. Egitura 
kristalizatuarekin loturiko hitzezko arrazoibidea, Gc; (c) zenbakizko arrazoibidea, Gq; (d) prozesamendu bisualarekin lotutako arrazoibide espaziala, Gv; eta (d) arrazoibide mekanikoa eta arrazoibide praktikoa, zeinak arrazoibide fluituarekin, Gf, eta idatziaren ulermenarekin, Grw, lotuta dauden. Gaitasun horiek guztiak ebaluatzeko asmoz, BPRk ataza desberdinak ditu; hala nola, analogiak, segidak eta problemen ebazketa-ariketak. Edukiaren aldetik, berriz, BPRk honako itemak ditu: esangurarik gabeko irudi geometrikoak (figuratibo-abstraktuak), hitzak (hitzezkoa), zenbaki-segidak (zenbakizkoa), kubo-mugimenduak (espaziala) eta egoera praktikoak (konkretu-praktikoak). Adimenaren bilakaera dela BPRk ataza, item eta forma desberdinak ditu, ikaslearen adinera egokituak.

Gaitasun intelektualei buruzko egituraren eztabaidarekin batera, xx. mendearen hasieratik, sexuaren araberako balizko desberdintasunak ere aztergai izan dira (Fryer eta Levitt, 2010; Lemos, Abad, Almeida eta Colom, 2013; Lohman eta Lakin, 2009), eta gaiak sortutako eztabaidak bizirik dirau. Argitaratutako ikerketek diotenez, adimenarekin loturiko berariazko ataletan desberdintasunak daude emakumezkoen eta gizonezkoen artean (Halpern et al., 2007). Oro har, emakumezkoek puntuazio altuagoak lortzen dituzte hitzezko gaitasunetan (Halpern, 1997; Lynn, Raine, Venables, Mednick eta Irwing, 2005; Johnson eta Bouchard, 2007), eta gizonezkoek, berriz, gaitasun espazialetan, arrazoibide abstraktuan eta zenbakizko gaitasunetan izaten dute errendimendu hobeagoa (Colom, Quiroga eta Juan-Espinosa, 1999; Geiser, Lehman eta Eid, 2008; Linn eta Petersen, 1985; Voyer, Voyer eta Bryden, 1995). Hala ere, ez dago adostasunik arrazoibide orokorrean desberdintasunak dauden ala ez ondorioztatzerakoan. Zenbaitek, gizonezkoak $g$ faktorean hobeto aritzen direla diote (Lynn, 2002; Jackson eta Rushton, 2006); beste zenbaitek, ordea, sexuen artean ez dagoela desberdintasunik ondorioztatzen dute (Dolan et al., 2006; van der Sluis et al., 2006.

Testuinguru horretan eta Euskal Herrian dagoen gabezia gainditzeko asmoarekin, ikerketaren helburuak hiru dira: a) BPR euskaratzea, b) euskaraturiko andanaren ezaugarri psikometrikoak frogatzea, eta c) sexuaren araberako desberdintasunak aztertzea.

\section{METODOA}

\section{Parte-hartzaileak}

Lagina Euskal Autonomia Erkidegoko 1923 ikaslez osaturik dago, 985 neska eta 938 mutil. Ikasleen adina 9 eta 22 urte bitartean dago, eta ikasleak BPRren formen arabera sailkatuta daude (Ikus 1. taula). Forma-1 osatu duten ikasleen adinaren batezbestekoa 10,32 da (DT =0,98); BPR bigarren forma egin dutenen batezbestekoa 13,51 da $(\mathrm{DT}=0,97)$, eta hiru- 
garren forma osatu dutenena, berriz, 16,28 urtekoa (DT = 1,07). Ikasleak 17 ikastetxetatik datoz eta guztiek D ereduan dihardute.

1. taula

Lagina

\begin{tabular}{c|c|c|c}
\hline Forma & Emakumezkoak & Gizonezkoak & Guztira \\
\hline BPR-1 & 320 & 343 & 663 \\
BPR-2 & 331 & 351 & 682 \\
BPR-3 & 334 & 244 & 578 \\
\hline Guztira & 985 & 938 & 1.923 \\
\hline
\end{tabular}

\section{Tresna}

BPRk adinaren arabera hiru forma ditu: BPR-1, BPR-2 eta BPR3. Lehenak lau eskala ditu, eta lehen hezkuntzako 4., 5., eta 6. mailetara egokitua dago (9-12 urte). BPR-2k bost ataza ditu, eta bigarren hezkuntzako lehen hiru urteak hartzen ditu (12-15 urte). BPR-3, bost eskalaz osatua dago eta 15-20 urteko gazteentzat egokitua dago. Ondoko taulak BPR forma bakoitzak hartzen dituen eskalak, atazak eta item kopurua jasotzen ditu.

2. taula

BPR. Arrazoiketa-proba andana. Formak, atazak eta itemak

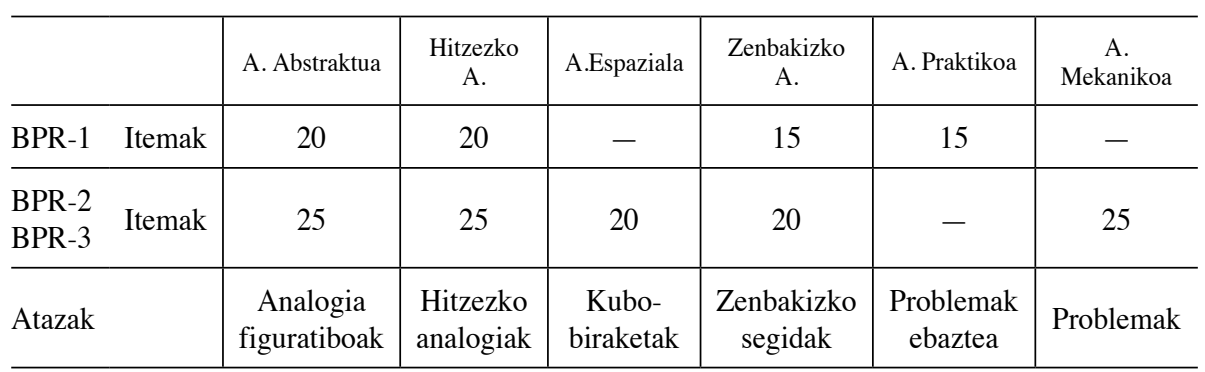

BPR euskaratzeko Nazioarteko Testen Komisioak emandako gomendioak jarraitu dira zehatz-mehatz (Elosua, 2003, 2005; Muñiz, Elosua eta Hambleton, 2013). Andana euskaratzeko aurrerantzeko-egokitze bikoitza deritzon teknika erabili da. Bi itzultzaile independentek andana euska- 
ratu ondoren, diziplina anitzeko lantaldea osatu zen eta bi bertsioen arteko adostasuna lantzeari ekin zitzaion. Lantaldean bi psikometra, bi itzultzaile eta lehen eta bigarren hezkuntzako bi irakasle aritu ziren. Egokitze-aldian eta itemen eduki semantikoen familiartasuna eta zailtasunak mantentze aldera, andanaren hitzezko atalean zenbait item aldatu ziren: BPR-1en 5 item, BPR-2n 5 item eta BPRko hirugarren forman 6 item.

\section{EMAITZAK}

3. taula

Ezaugarri psikometrikoak

\begin{tabular}{l|c|c|c|c|c|c|c|c|c}
\hline & \multicolumn{3}{|c|}{ Forma 1 } & \multicolumn{3}{c|}{ Forma 2 } & \multicolumn{3}{c}{ Forma 3 } \\
\cline { 2 - 10 } & $\alpha$ & $\operatorname{Var} \%$ & $\lambda$ & $\alpha$ & $\operatorname{Var} \%$ & $\lambda$ & $\alpha$ & $\operatorname{Var} \%$ & $\lambda$ \\
\hline A.Abstraktuak & 0,88 & 0,29 & 0,65 & 0,89 & 0,29 & 0,55 & 0,86 & 0,25 & 0,63 \\
Hitzezko A. & 0,85 & 0,23 & $0,79(0,05)$ & 0,86 & 0,22 & $0,63(0,06)$ & 0,87 & 0,22 & $0,71(0,06)$ \\
Zenbakizko A. & 0,92 & 0,45 & $0,70(0,05)$ & 0,93 & 0,45 & $0,65(0,06)$ & 0,88 & 0,31 & $0,54(0,05)$ \\
A.Praktikoa & 0,92 & 0,53 & $0,79(0,05)$ & & & & & & \\
A.Espaziala & & & & 0,88 & 0,28 & $0,75(0,07)$ & 0,85 & 0,25 & $0,73(0,06)$ \\
A.Mekanikoa & & & & 0,79 & 0,16 & $0,50(0,06)$ & 0,81 & 0,19 & $0,39(0,05)$ \\
\hline
\end{tabular}

Oharra. $\alpha$ : fidagarritasun-koefizientea. $\lambda$ : saturazio faktorialak; parentesi artean zenbatespen-erroreak.

\section{Oinarrizko ezaugarri psikometrikoak}

\section{Fidagarritasuna}

Hezkuntza-ebaluazioan eta ebaluazio psikologikoan erabiliko den tresna orok izan behar du gutxienezko fidagarritasuna. Fidagarritasuna, fidagarritasun-koefizientearen bitartez ematen da, eta horren balioa 0-1 tartean dago (Elosua, 2005). Zenbat eta altuagoa izan koefizientea, orduan eta fidagarriagoak izango dira testaren bitartez lortzen diren puntuazioak. BPRko eskala bakoitzaren fidagarritasuna puntuazioen barne-kontsistentzia aztertuz zenbatetsi da; erabilitako prozedura alpa ordinala da. Hirugarren taulan ikusten denez, barne-kontsistentziaren balioak 0,79 eta 0,93 bitartean daude. Forma bakoitzean baliorik altuenak zenbakizko eskale$\tan$ lortu dira $\left(\alpha_{\text {Forma-1 }}=0,92 ; \alpha_{\text {Forma- } 2}=0,93 ; \alpha_{\text {Forma-3 }}=0,88\right)$, eta baxuenak, berriz, arrazoibide mekanikoarekin loturiko eskaletan $\left(\alpha_{\text {Forma- } 2}=0,79\right.$; $\alpha_{\text {Forma-3 }}=0,81$ ). 


\section{Dimentsiobakartasuna}

Eskala bakoitzak esangura bakarra duela aztertzeko datuen dimentsiobakartasuna bermatu behar da, eta horretarako prozedurarik ohikoena faktore-analisia da. Faktore-analisiak, kasu horretan, eskala bakoitzean egitura nagusi bat dagoen aztertzen du. Faktore-analisiaren emaitzak interpretatzeko baliorik esanguratsuenetakoa azalduriko bariantza-proportzioa da (Ikus 3. taula). Eskala bat dimentsiobakarra da balio hori \%20tik gorakoa bada. BPR andanarekin lortu diren balioei erreparatuz, argi ikusten da zenbakizko arrazoibideek dituztela baliorik altuenak $(0,45 ; 0,45$; $0,31)$; balio baxuenak, berriz, arrazoibide mekanikoarekin lotuta daude $(0,16 ; 0,19)$.

\section{Arrazoibide orokorra}

BPR sortzeko erabili den eredu teorikoaren arabera, berariazko arrazoibideek arrazoibide orokorra osatzen dute. Hori aztertzeko, faktore-analisi baieztatzailea deritzon teknika erabili dugu. Analisiaren emaitzak hirugarren taulan irakur daitezke, $\lambda$ sinboloaren zutabean. Hor agertzen diren balioak saturazioak dira, hau da, eskala bakoitzaren eta arrazoibide orokorraren arteko erlazioak. Balio horiek korrelazioak balira bezala interpreta daitezke; $0-1$ balio tartean daude eta zenbat eta balio altuagoa orduan eta erlazio estuagoa. Balio guztiak dira estatistikoki esanguratsuak eta 0,55 etik gorakoak; arrazoibide mekanikoari dagozkionak salbu $\left(\lambda_{\text {Forma-2 }}=0,5 ; \lambda_{\text {Forma-3 }}=0,39\right)$. Balio horiek garrantzitsuak badira ere, faktore-analisi baieztatzailea interpretatzeko doitze-indizeak hartu behar dira kontuan. Gure kasuan, ohiz erabiltzen diren doitze-indizeak baikorrak dira eta, ondorioz, eredu teorikoa eta datuak bat datozela esan daiteke; SRMR indizeak 0,05 balioaren azpitik daude (Forma-1 $=0,2$; Forma-2 $=0,04$; Forma-3 $=0,03$ ) eta CFI indizeak, berriz, 0,93tik gora daude (Forma-1 $=0,99$; Forma-2 $=, 93$; Forma-3 $=0,98$ ).

\section{Generoaren araberako desberdintasunak}

Generoaren araberako desberdintasunak ikertzeko eskala bakoitzaren batezbesteko aritmetikoa kalkulatu da (Ikus ondorengo irudia eta 4. taula), eta batezbestekoen arteko desberdintasunen esangura estatistikoa aztertu da; horretaz gain, desberdintasun horien tamaina zer-nolakoa den deskribatuko duen estatistiko bat erabili da: Hedges-en $g$. Estatistiko horren arabera, bi taldeen arteko aldea 0,2 baino baxuagoa bada alde hori baztergarria da. 
Ikasle gazteen artean (forma-1, 9-11 urte), desberdintasunak daude zenbakizko arrazoibidean $\left(\mathrm{B}_{\text {Mutilak }}=8,90 ; \mathrm{B}_{\text {Neskak }}=8,07\right)$, eta arrazoibide praktikoan $\left(B_{\text {Mutilak }}=8,5 ; B_{\text {Neskak }}=9,33\right)$. Lehen kasun, gizonezkoek puntuazio altuagoak lortzen dituzte eta bigarrengoan, berriz, neskek hobeto dihardute. Hala ere, desberdintasunen arteko esangura praktikoa aztertzen duen estatistikoaren arabera (Hedges-en $g$ ) desberdintasunen arteko tamaina txikia da bi kasuetan $\left(g_{\text {hitzezkoa }}=-.23 ; g_{\text {praktikoa }}=.26\right)$. Zenbakizko arrazoibidearekin jarraituz, datuek ez zuten desberdintasunik erakutsi BPRko bigarren forman $\left(\mathrm{B}_{\text {Mutilak }}=8,44 ; \mathrm{B}_{\text {Neskak }}=8,05\right)$; hirugarren forman, ordea, mutilen aldeko desberdintasunak ikusi ziren $\left(\mathrm{B}_{\text {Mutilak }}=10,22 ; \mathrm{B}_{\text {Neskak }}=9,52\right)$, nahiz horien tamaina hutsala izan $\left(g_{\text {Forma-2 }}=.09 ; g_{\text {Forma-3 }}=-.19\right)$.

Hitzezko gaitasunari dagokionez, balioak nesken alde azaldu ziren andanaren bigarren forman $\left(\mathrm{B}_{\text {Mutilak }}=13,76\right.$; $\left.\mathrm{B}_{\text {Neskak }}=14,66\right)$, nahiz efektuaren tamaina txikia izan $(\mathrm{g}=.21)$. Bestelako alderatze guztiak ez ziren estatistikoki esanguratsuak izan; hala ere, eta espero zitekeen bezala, emakumezkoek lortutako balioak altuagoak izan ziren BPRko bi forme$\tan \left(\mathrm{B}_{\text {Mutilak Forma-1 }}=11,70 ; \mathrm{B}_{\text {Neskak Forma-1 }}=12,18 ; \mathrm{B}_{\text {Mutilak Forma-3 }}=15,21\right.$; $\left.\mathrm{B}_{\text {Neskak Forma-2 }}=15,39\right)$.

Arrazoibide mekanikoan mutilen batezbestekoak altuagoak izan ziren neskenak baino, bai andanaren bigarren forman, bai hirugarrengoan ere $\left(\mathrm{B}_{\text {Mutilak Forma-2 }}=10,15 ; \mathrm{B}_{\text {Neskak Forma-2 }}=9,36 ; \mathrm{B}_{\text {Mutilak Forma-3 }}=10.18 ; \mathrm{B}_{\text {Neskak }}\right.$ Forma-2 $=8,98)$. Desberdintasunen tamainari dagokionez, desberdintasun azpimarragarriena hirugarren formari loturik dago $\left(\mathrm{g}_{\mathrm{Form} 3}=-.36\right)$.

Arrazoibide espazialean sexuaren araberako desberdintasunak behatu ziren $(\mathrm{p}<.05)$. Emakumezkoek, 12-15 urte tartean, batezbesteko altuagoak lortu zituzten gizonezkoek baino $\left(\mathrm{B}_{\text {Mutilak }}=11,02 ; \mathrm{B}_{\text {Neskak }}=11,75\right)$; baina alderantzizko emaitzak ikusi ziren ikasle zaharrenen artean; hor gizonezkoek hobetu jardun zuten emakumezkoek baino $\left(\mathrm{B}_{\text {Mutilak }}=11,19\right.$; $\left.\mathrm{B}_{\text {Neskak }}=10,54\right)$. Hala ere, bi kasuetan desberdintasunek ez zuten esangura praktikorik izan $\left(\mathrm{g}_{\text {Forma-2 }}=.16 ; \mathrm{g}_{\text {Forma-3 }}=-.16\right.$ ).

Arrazoibide abstraktuan neskek puntuazio altuagoak lortu zituzten mutilek baino $\left(\mathrm{B}_{\text {Mutilak Forma-1 }}=12,59 ; \mathrm{B}_{\text {Neskak Forma-1 }}=13,00\right.$; $\mathrm{B}_{\text {Mutilak Forma-3 }}=14,64 ; \mathrm{B}_{\text {Neskak Forma-2 }}=15,10 ; \mathrm{B}_{\text {Mutilak Forma-3 }}=13,04$; $\left.\mathrm{B}_{\text {Neskak Forma-3 }}=13,10\right)$, baina desberdintasunak ez ziren estatistikoki esanguratsuak $(\mathrm{p}>.05)$. 
4. taula

Sexuaren araberako desberdintasunak

\begin{tabular}{|c|c|c|c|c|c|c|}
\hline \multirow{2}{*}{ BPR } & \multicolumn{2}{|c|}{ Emakumezkoak } & \multicolumn{2}{|c|}{ Gizonezkoak } & \multirow{2}{*}{$\begin{array}{l}\text { Desberdintasunak } \\
\text { (Student-en t) } t\end{array}$} & \multirow{2}{*}{$\begin{array}{l}\text { Efektuaren tamaina } \\
\text { (Hedges-n g) } \\
95 \% \text { CI }\end{array}$} \\
\hline & Batezbestekoa & DT & Batezbestekoa & DT & & \\
\hline \multicolumn{7}{|c|}{ A. Abstraktua } \\
\hline Forma-1 & 13,00 & 3,29 & 12,59 & 3,60 & $\mathrm{t}(654)=1,52 ; \mathrm{p}=, 12$ &, $11[-03,27]$ \\
\hline Forma-2 & 15,10 & 3,76 & 14,64 & 3,66 & $\mathrm{t}(674)=1,59 ; \mathrm{p}=, 11$ &, $12[-, 02,, 27]$ \\
\hline Forma-3 & 13,10 & 3,02 & 13,04 & 3,61 & $\mathrm{t}(570)=0,19 ; \mathrm{p}=, 84$ &, $01[-, 14,, 18]$ \\
\hline \multicolumn{7}{|l|}{ Hitzezko A. } \\
\hline Forma-1 & 12,18 & 3,71 & 11,70 & 3,61 & $\mathrm{t}(652)=1,67 ; \mathrm{p}=, 09$ &, $13[-, 02,, 28]$ \\
\hline Forma-2 & 14,66 & 4,06 & 13,76 & 4,18 & $\mathrm{t}(669)=2,82 ; \mathrm{p}=, 005$ &, $21[, 06,37]$ \\
\hline Forma-3 & 15,39 & 3,71 & 15,21 & 3,97 & $\mathrm{t}(565)=0,54: \mathrm{p}=, 58$ &, $05[-, 11,, 28]$ \\
\hline \multicolumn{7}{|c|}{ A. Espaziala } \\
\hline Forma-2 & 11,75 & 4,27 & 11,02 & 4,47 & $\mathrm{t}(664)=2,15 ; \mathrm{p}=, 03$ &, $16[, 01,31]$ \\
\hline Forma-3 & 10,54 & 3,53 & 11,19 & 4,11 & $\mathrm{t}(573)=-2,01: \mathrm{p}=, 04$ &,$- 16[-, 33,-, 00]$ \\
\hline \multicolumn{7}{|c|}{ Zenbakizko A. } \\
\hline Forma-1 & 8,07 & 3,48 & 8,90 & 3,52 & $\mathrm{t}(659)=-3,02 ; \mathrm{p}=, 003$ &,$- 23[-, 38,-, 08]$ \\
\hline Forma-2 & 8,05 & 4,08 & 8,44 & 4,65 & $\mathrm{t}(653)=-1,16 ; \mathrm{p}=, 24$ & $-, 09,[-, 24,06]$ \\
\hline Forma-3 & 9,52 & 3,49 & 10,22 & 3,57 & $\mathrm{t}(570)=-2,33: \mathrm{p}=, 02$ &,$- 19[-, 36,-, 03]$ \\
\hline \multicolumn{7}{|c|}{ A. Mekanikoa } \\
\hline Forma-2 & 9,36 & 3,29 & 10,15 & 3,77 & $\mathrm{t}(659)=-1,87 ; \mathrm{p}=, 06$ &,$- 14[-, 29,00]$ \\
\hline Forma-3 & 8,98 & 2,94 & 10,18 & 3,59 & $\mathrm{t}(567)=-4,34 ; \mathrm{p}<, 001$ &,$- 36[-, 52,-, 19]$ \\
\hline \multicolumn{7}{|l|}{ A. Praktikoa } \\
\hline Forma-1 & 9,33 & 2,72 & 8,55 & 3,06 & $\mathrm{t}(651)=3,42 ; \mathrm{p}=, 001$ & ,26[,11,,42] \\
\hline
\end{tabular}



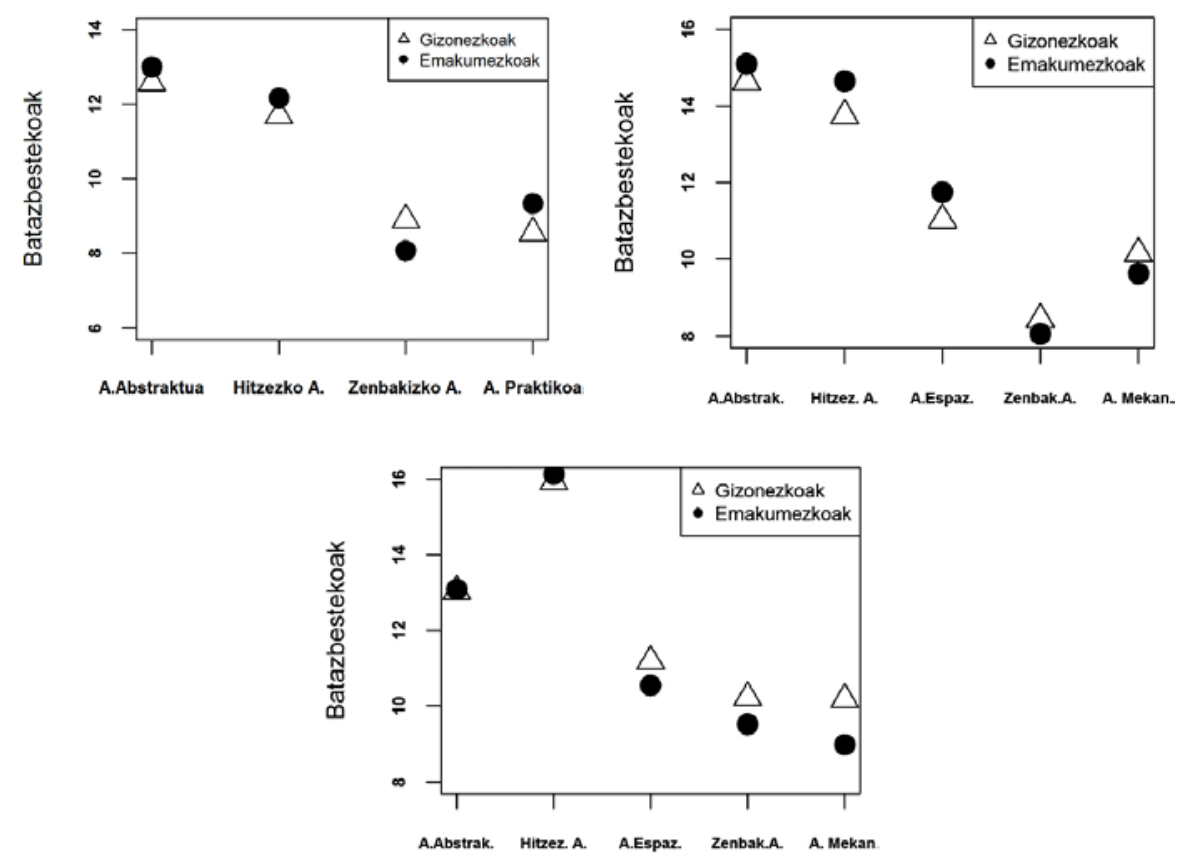

2. irudia

Arrazoiketa-proba Andana. Forma-1, Forma-2, Forma-3.

Sexuaren araberako desberdintasunak

\section{ONDORIOAK}

Test baten baliagarritasunak aztertzen du zein puntutaraino dagoen bermatua test horren bitartez lortutako puntuazioak interpretatzea (AERA, APA eta NCMEA, 2014). BPR, eta horren formak, gaitasun kognitiboa aztertzeko sortu dira eta, ondorioz, baliagarritasunaren azterketak argitu egin beharko du forma horiek sortzeko erabili den eredu teorikoa eta forma horiek aplikatuz lortzen diren puntuazioak bat datozen. Lan honetan BPR andana osatzen duten hiru formen barne-kontsistentzia eta barne-egitura arakatu dira. Barne-kontsistentziari dagokionez, eskala guztietan lortutako koefizienteak 0,79 eta 0,93 balioen artean daude. Barne-kontsistentziarik ahulena bigarren formako arrazoibide mekanikoak du $(0,79)$, eta fidagarritasun-koefizienterik altuenak, berriz, zenbakizko arrazoibide eskaletan lortu dira $\left(\alpha_{\text {Forma-1 }}=0,92 ; \alpha_{\text {Forma-2 }}=0.93 ; \alpha_{\text {Forma-3 }}=0.88\right)$. Emaitza horiek bat datoz beste lurraldeetan BPR andanarekin egindako ikerketekin (Almeida eta Lemos, 2006; Baumgartl eta Primi, 2006; Elosua eta Mujika, 2015). 
Eskala bakoitzak aldagai bat eta bakarra neurtzen duelako hipotesia ere aztertu dugu; hori baieztatu gabe ez litzateke zuzena izango eskala-balioak erabiltzea. Horretarako analisi faktoriala erabili dugu; arrazoibide mekanikoaren balioak mugan baldin badaude ere, beste eskala guztientzat lortutako bariantza-proportzioak baikorrak dira. BPRren egituran sakonduz, puntuazioak eta eredu teorikoa (1. irudia) zein puntutaraino datozen bat aztertu dugu; hau da, galdera honi erantzun nahi diogu: Zilegi da ataza bakoitzean lortzen diren puntuazioak batzea ikaslearen arrazoibide orokorra deritzona ebaluatzeko? Emaitzek baietz diote. Ikerketa psikometrikoan ohiz erabiltzen diren indikatzaileak baikorrak dira; ataza bakoitzaren berariazkotasuna mantentzen da, baina aldi berean atazen arteko erlazioak indartsuak dira. Erlazio horiek egitura nagusi bat definitzen dute, arrazoibide orokorra.

Andana psikometrikoki sendoa dela frogatuta, sexuaren araberako desberdintasunen azterketari ekin diogu. Aurkitu ditugun emaitzak bat datoz gaiari buruz argitaratu diren ikerketekin. Lan honetan egindako analisien arabera, gizonezkoek emakumezkoek baino puntuazio altuagoak lortzen dituzte zenbakizko gaitasunetan (Hyde, 2005; Larrañaga, Elosua eta Chinchilla, 2014; Spelke, 2005); hitzezko gaitasunetan, berriz, emakumezkoek hobeto dihardute (Halpern et al., 2007). Bi ondorio orokor horiek, ordea, zertxobait zehaztu behar dira. Batetik, nabarmentzekoa da desberdintasunek norabide bera izan dutela hiru formetan; hau da, beti emakumezkoen alde hitzezko arrazoibidean, eta beti gizonezkoen alde zenbakizko arrazoibidean. Bestetik, alderatze guztietan, zenbatetsi den efektuaren tamaina txikia izan da.

Arrazoibide abstraktuari dagokionez, ondoriorik aipagarriena sexuaren araberako desberdintasunik eza da. Batezbestekoen artean behatu diren desberdintasunak ez dira ez estatistikoki ez praktikoki esanguratsuak. Mutilek eta neskek berdin dihardute. Arrazoibide espazialaren azterketan ikusi diren desberdintasunak estatistikoki hutsalak izan dira eta praktikoki esangurarik gabeak.

Arrazoibide mekanikoak arreta berezia eskatzen du. Batetik, arrazoibide mekanikoa aztertzen duten bi eskalen ezaugarri psikometrikoak ez dira izan beste eskaletan lortutakoak bezain sendoak, eta, bestetik, arrazoibide mekanikoan ikusi dira sexuaren araberako desberdintasunik nabarmenenak. Ikuspuntu teoriko batetik, arrazoibide-proba andanaren ataza mekanikoak eta espazialak zenbait gaitasun bisuoespazialen barne sar daitezke, eta horietan badirudi gizonezkoek emakumezkoek baino puntuazio altuagoak ateratzen dituztela (Voyer, Voyer eta Bryden, 1995). Bisualizazio espazialari buruzko zenbait meta-analisik erakutsi du sexuen arteko desberdintasunik nabarmenenak kuboen errotazio atazekin loturik daudela, baina, nahiz eta ataza hori den BPRko arrazoibide espazialeko eskalan dagoena, ikerketa honetan behaturiko desberdintasunak baztergarriak izan dira. Emaitza horrek, eta arrazoibide mekanikoaren eskalaren portaerak, bi 
eskala horiekin batera arrazoibide bisualarekin zerikusia duen faktorea dagoela pentsatzera garamatza; hori aztertzeko ikerketa gehiago behar dira eta horietan BPRren hizkuntza-bertsio desberdinak kontuan hartzea komeniko litzateke.

Oro har esan daiteke arrazoibide-proba andana baliagarria dela arrazoibide-gaitasun orokorra zein berariazko gaitasunak neurtzeko. Erabileraren aldetik, gure ikasleak ebaluatzeko tresna aparta da: batetik, euskaraz egina dago; bestetik, eredu teoriko sendo baten gainean sortu da; eta, azkenik, adin ibiltarte zabala hartzen du bere baitan. Euskarazko BPR andanak modu azkar eta fidagarrian ebaluatzen ditu eskola-errendimenduarekin loturiko gaitasun nagusienak, eta euskal ikasleen ebaluazio kognitiboaren alorrean zegoen hutsune nabarmena betetzera dator.

\begin{abstract}
Although tests intended to assess cognitive abilities are the most used tests in Europe, there are not psychometrically well constructed reasoning batteries in Basque language which cover a wide age range. Taking into account that important deficiency, the aim of this work was threefold: a) to adapt the Reasoning Test Battery (BPR) to Bas$q u e, b)$ to assess its psychometric properties, and c) to analyze gender differences. The theoretical foundation of the BPR is the hierarchical organization of cognitive abilities and therefore combines a general cognitive factor and specific factors associated with abstract, numerical, verbal, practical, spatial and mechanical reasoning. The battery has three forms which cover an age range from 9 to 22. The study was based on a sample of 1923 students. Overall the results concluded good psychometric properties of the battery in terms of reliability and internal structure. Differences among gender in verbal and numerical dimensions were found, although the effect sizes were negligible. Mechanical reasoning was the origin of the biggest differences between males and females.
\end{abstract}

Keywords: reasoning test, gender differences, Basque, BPR.

A pesar de que en Europa los tests para la evaluación de las capacidades cognitivas son los más utilizados, no existe hasta el momento una batería de pruebas de razonamiento en euskera con propiedades psicométricas garantizadas y destinada a cubrir un amplio rango de 
edad. Con la intención de cubrir esa grave carencia esta investigación tiene tres objetivos: a) adaptar al euskera la Batería de Pruebas de Razonamiento (BPR); b) analizar sus propiedades psicométricas, y c) estudiar las posibles diferencias en función del sexo. La BPR se construye sobre el modelo teórico de la organización jerárquica de las capacidades cognitivas, y como tal, la batería permite evaluar la capacidad cognitiva general así como factores de razonamiento específicos: razonamiento abstracto, razonamiento numérico, razonamiento verbal, razonamiento espacial y razonamiento mecánico. La muestra de estudio en esta investigación está formada por 1923 estudiantes con edades comprendidas entre los 9 y los 22 años. Los resultados muestran que la BPR presenta propiedades psicométricas adecuadas, tanto en lo que respecta a la fiabilidad de las puntuaciones como a su estructura interna. Se han observado diferencias relacionadas con el género en las pruebas de razonamiento verbal y razonamiento numérico; aunque en ambos casos el tamaño del efecto ha sido pequeño. Las diferencias mayores están relacionadas con al razonamiento mecánico.

Palabras clave: razonamiento cognitivo, diferencias en función del sexo, euskera, BPR.

Bien qu'en Europe, les tests pour évaluer les capacités cognitives sont les plus couramment utilisés, il n'existe pas à ce jour une batterie de tests de raisonnement en basque avec des propriétés psychométriques garantisées et qui peuvent couvrir une large gamme d'âge. A fin de couvrir ce manque grave, cette recherche a trois objectifs: a) l'adaptation au basque du Reasoning Test Battery (BPR); b) l'analyse de ses propriétés psychométriques, et c) l'étude des éventuelles différences fondées sur le sexe. Le BPR est construit sur le modèle théorique de l'organisation hiérarchique des capacités cognitives, et en tant que telle, la batterie évalue la capacité cognitive générale ainsi que les facteurs de raisonnement spécifique: raisonnement abstrait, raisonnement numérique, raisonnement verbal, le raisonnement spatial et le raisonnement mécanique. L'échantillon de l'étude se compose de 1923 élèves âgés de 9 à 22 ans. Les résultats montrent que le BPR a des propriétés psychométriques, à la fois en ce qui concerne les scores de fiabilité et de sa structure interne. Des differences liées au sexe ont été observés dans les tests de raisonnement verbal et le raisonnement numérique; bien que dans les deux cas, la taille de l'effet était faible. Les différences les plus importantes sont liées au raisonnement mécanique.

Mots-clé : capacités cognitives, différences fondées sur le sexe, euskara, BPR 


\section{ERREFERENTZIAK}

Almeida, L.S., eta Lemos, G. (2006). Batería de provas de raciocínio: manual técnico . Braga: Universidade do Minho, Centro de Investigação em Psicologia.

American Educational Research Association, American Psychological Association, eta National Council on Measurement in Education (2014). Standards for Educational and Psychological Testing. Washington: AERA.

Baumgartl, V.O., eta Primi, R. (2006). Evidences on the validity of the Battery of Reasoning Tests (BPR-5) for employment selection. Psicologia: Reflexão e Crítica, 19, 246-251.

Carroll, J.B. (2003). The higher-stratum structure of cognitive abilities: Current evidence supports g and about 10 brad factors. In H. Nyborg (ed.), The Scientific Study of Generallintelligence: Tribute to Arthur R. Jensen (pp. 5-21). Amsterdam: Pergamon.

Cattell, R.B. (1963). Theory of fluid and crystallized intelligence: A critical experiment. Journal of Educational Psychology, 54, 1-22.

Cattell, R.B. (1971). Intelligence: Its structure, growth and action. Boston, MA: Houghton Mifflin.

Colom, R., Quiroga, M. A., eta Juan-Espinosa, M. (1999). Are cognitive sex differences disappearing? Evidence from Spanish populations. Personality and Individual Differences, 27, 1189-1195.

Dolan, C.V., Colom, R., Abad, F.J., Wicherts, J.M., Hessen, D.J., eta van de Skyusm S. (2006). Multi-group covariance and mean structure modeling of the relationship between the WAIS-III common factors and sex and educational attainment in Spain. Intelligence, 34, 193-210.

Elosua, P. (2003). Testen euskaratzea. Balizko alborapenaren iturriak. Tantak, 30, 17-38.

Elosua, P. (2005). Psikometria. Leioa: EHU

Elosua, P., eta Almeida, L.S. (2016). Batería de Pruebas de Razonamiento. Madril: TEA

Elosua, P., eta Iliescu, D. (2012). Tests in Europe. Where we are and where we should to go. International Journal of Testing, 12, 157-175.

Elosua, P., eta Mujika, J. (2015). Internal structure and gender invariance of the Spanish version of the reasoning test battery. Spanish Journal of Psychology, 18, 296-302.

Fryer, R.G., Jr. eta Levitt, S.D. (2010). An Empirical Analysis of the Gender Gap in Mathematics. American Economic Journal-Applied Economics, 2, 210-240.

Geiser, C., Lehmann, W., eta Eid, M. (2008). A note on sex differences in mental rotation in different age groups. Intelligence, 36, 556-563.

Guilford, J. P. (1967). The nature of human intelligence. New York: McGraw-Hill.

Halpern, D. (1997). Sex differences in intelligence: Implications for education. American Psychologist, 52, 1091-1102.

Halpern, D.F., Benbow, C., Geary, D.C., Gur, R.C., Hyde, J.S., eta Gernsbacher, M.A. (2007). The science of sex differences in science and mathematics. Psychological Science in the Public Interest, 8, 1-51.

Horn, J., eta Noll, J. (1997). Human cognitive capabilities: Gf-Gc theory. In D. P. Flagnagan, J. L. Genshaft, eta P.L. Harrison (eds.), Contemporary intellectual assessment: Theories, tests, and issues. New York, NY: The Guilford Press. 
Hyde, J. S. (2005). The gender similarities hypothesis. American Psychologist, 60, 581-592.

Jackson, D. N., eta Rushton, J. P. (2006). Males have greater g: Sex differences in general mental ability from 100,000 17- to 18-year-olds on the Scholastic Assessment Test. Intelligence, 34, 479-486.

Johnson, W., eta Bouchard, T. (2007). Sex differences in mental abilities: g masks the dimensions on which they lie. Intelligence, 35, 23-39.

Larrañaga, A., Elosua, P., eta Chinchilla, J. (2014). Matematikarako konpetentzia eta generoa. Tantak, 26, 27-39.

Lemos, G., Abad, F. J., Almeida, L.S., eta Colom, R. (2013). Sex differences on g and non-g intellectual performance reveal potential sources of STEM discrepancies, Intelligence, 41, 11-18.

Linn, M. C., eta Petersen, A. C. (1985). Emergence and characterisation of gender differences in spatial abilities: A meta-analysis. Child Development, 56, 14791498.

Lohman, D.F., eta Lakin, J. (2009). Consistencies in sex differences on the cognitive abilities test across countries, grades, test forms, and cohorts. British Journal of Educational Psychology, 79, 389-407.

Lynn, R. (2002). Sex differences on the Progressive Matrices among 15-16 year olds: Some data from South Africa. Personality and Individual Differences, 33, 669-673.

Lynn, R., Raine, T. A., Venables, P. H., Mednick, S. A., eta Irwing, P. (2005). Sex differences on the WISC-R in Mauritius. Intelligence, 3, 527-533.

Meuris, G. (1969). Tests de raisonnement différentiel. Bruxelles: Editest.

McGrew, K. S. (2005). The Cattell-Horn-Carroll theory of cognitive abilities: Past, present, and future. In D. P. Flanagan eta P. L. Harrison (Eds.), Contemporary intellectual assessment: Theories, tests, and issues (2nd ed., pp. 136182). New York, NY: Guilford Pres

Muñiz, J., Elosua, P., eta Hambleton, R.K. (2013). Directrices para la traducción y adaptación de los tests: Segunda edición [International Test Commission guidelines for test translation and adaptation. Second edition]. Psicothema, 25, 149-155.

Schneider, W. J., eta McGrew, K. S. (2012). The Cattell-Horn-Carroll Model of Intelligence. In D. P. Flanagan, eta P. L. Harrison (Eds.), Contemporary intellectual assessment: Theories, tests, and issues (3rd ed., pp. 99-144). New York, NY: Guilford Press.

Spelke, E.S. (2005). Sex differences in intrinsic aptitude for mathematics and science? A critical review. American Psychologist, 60, 950-958.

Spearman, C. (1927). The abilities of man. New York: Macmillan.

Thurstone, L. L. (1938). Primary mental abilities. Chicago: University of Chicago Press.

Van der Sluis, S., Posthuma, D., Dolan, C.V., de Geus, E.J.C., Colom, R., eta Boomsma, D.I. (2006). Sex differences on the Dutch WAIS-III. Intelligence, 34, 273-289.

Vernon, E. (1961). The Structure of Human Abilities. London: Methuen.

Voyer, D., Voyer, S., eta Bryden, M. P. (1995). Magnitude of sex differences in spatial abilities: A meta-analysis and consideration of critical variables. Psychological Bulletin, 117, 250-270. 